\title{
'Protozoan' infections in the immunocompromised patient-the parasites and their diagnosis
}

\author{
R. W. A. GIRDWOOD \\ Scottish Parasite Diagnostic Laboratory, Department of Bacteriology, Stobhill General Hospital, Glasgow G21 \\ 3UW
}

\section{Introduction}

The word 'protozoan' in the title of this overview is in quotation marks because there is new evidence that Pneumocystis carinii, for long regarded by the majority of microbiologists as being a protozoan of undefined status, should now be designated as a member of the Fungi (Edman et al., 1988). In addition, the microsporidia, a unique group of eukaryotes which have been found recently to produce human infections, are sufficiently unusual to warrant allocation to a new protistan phylumMicrospora (Canning and Hollister, 1987). Nevertheless, the terms protozoa and protozoan will be used in this text for convenience-even for these organisms.

The downward spiral of poverty and malnutrition predisposing to parasitic infections which further impoverish the nutritional status and resistance of the host can be taken as the classical, and still numerically the most important, example of immunocompromisation and parasitic infection. This principally third-world situation where gastrointestinal helminths predominate (e.g., Ascaris lumbricoides, Trichuris trichiura, the hookworms and Schistosoma mansoni) has been overshadowed to some degree by the relatively recent recognition of the acquired-immunodeficiency syndrome (AIDS) epidemic in the Americas, Europe and Africa. Indeed, it was the recognition of the increased occurrence and severe clinical manifestations of otherwise rare parasitic infections that led to the recognition of AIDS. In this instance, the infectious agents were the protozoans, $P$. carinii, Toxoplasma gondii and Cryptosporidium spp. Thus, in the Western World at least, protozoa as opposed to helminths have come to be the predominant parasitic infections in immuno-compromised patients. For the purpose of this article the immunocompromised host can be defined loosely as an individual whose immunological defences are im-

Received 9 Jan. 1989; accepted 14 Mar. 1989. paired to a degree such that protection against the development of clinical infection is reduced. Broad groups of potentially immunocompromising conditions are listed in table I. Whilst in specific instances the precise nature of the underlying medical or immunological defect will have a direct bearing on the species of the infecting agent and the clinical manifestations and outcome produced, it can be stated that, generally, conditions which depress cell-mediated immunity predominantly increase vulnerability to parasitic infections. Many of the protozoa which account for a major proportion of infections and represent a major cause of mortality in such individuals would be considered to have intrinsically low human pathogenicity in the immunocompetent. In at least one example, i.e., $P$. carinii, it might be argued that disease (as opposed to infection) does not occur in the immunocompetent host. Clinical infections due to protozoa in the immunocompromised patient may represent reactivation and dissemination of already present subclinical infections or increased vulnerability to re-infection and systemic invasion by organisms of low pathogenicity due to the waning of acquired immunity. Thus, with toxoplasmosis or pneumocystosis it is the high prevalence of subclinical infection in the healthy population, and the impaired immunological response of the compromised host, frequently in combination with the unknown previous-exposure history of that host,

Table I. Examples of immunocompromising conditions

\footnotetext{
Pregnancy

Age, e.g., prematurity, old age

Congenital immunological defects, e.g., agamma-globulinaemia Infections, e.g., HIV, measles, malaria, leishmania Malnutrition

Neoplasia, e.g., lymphatic leukaemia, Hodgkin's disease

Therapeutic suppression, e.g., cytotoxics and steroids for tumour therapy or transplant surgery

Collagen-vascular diseases, e.g., systemic lupus erythematosus Surgery, e.g., splenectomy
} 
which combine to make definitive diagnosis of such systemic infections so difficult. In these instances, interpretation of antibody titres or even the detection of parasite antigens is fraught with problems. Therefore, it is essential to be aware of the vulnerability of immunocompromised patients to particular protozoan infections and, where possible when immunosuppressing procedures are about to be instituted, "base-line" samples should be taken so that any subsequent changes in antibody or antigen levels have a greater chance of useful interpretation.

The protozoa and the systems which they affect predominantly are outlined in table II. $T$. gondii, $P$. carinii and Cryptosporidium spp. are, numerically and clinically, the most important protozoans in immunocompromised patients. In particular, they are major causes of morbidity and mortality in AIDS patients. Accordingly, these organisms will be discussed in more detail than the Acanthamoeba spp., the microsporidia and Babesia divergens which, as yet, account for only small numbers of infections in such patients. Giardia lamblia, Isospora belli and Leishmania donovani are discussed because, although they have long been known as important agents of human disease, it is only recently that the immunocompromised patient has been recognised as being more vulnerable to such infections.

\section{Pneumocystis carinii}

The recent phylogenic analysis of pneumocystis 16S-like, ribosomal RNA (Edman et al., 1988), if confirmed, will place $P$. carinii as a member of the Fungi.

Nevertheless, the life-cycle of the organism has yet to be elucidated and the current terminology used to describe the various recognised morphologies allude to the previously adhered-to belief that $P$. carinii was of protozoan lineage. Thus, thickwalled cysts, 4-7 $\mu \mathrm{m}$ in diameter, containing up to

Table II. Protozoa and the systems predominantly affected in immunocompromised patients

\begin{tabular}{ll}
\hline System & Protozoa \\
\hline Respiratory & $\begin{array}{l}\text { Pneumocystis carinii } \\
\text { Toxoplasma gondii } \\
\text { Central Nervous }\end{array}$ \\
Gastrointestinal & $\begin{array}{l}\text { Cryptosporidium } \text { spp. } \\
\text { Isospora belli } \\
\text { Giardia lamblia } \\
\text { Leishmania donovani } \\
\text { Haemopoietic }\end{array}$ \\
& Babesia divergens \\
\hline
\end{tabular}

eight sporozoites are regularly described. It is thought that released sporozoites develop into thinwalled trophozoites ( $1-5 \mu \mathrm{m}$ diameter) and that the trophozoite in turn matures to form a thick-walled cyst. In addition, crescent-shaped cyst forms are encountered. Elegant transmission electronmicroscope and freeze-fracture electronmicroscope studies have been carried out by Yoneda and Walzer $(1980,1983)$.

$P$. carinii was first described by Chagas in 1907 in the lungs of guinea pigs. Human infection was first recognised in Central Europe (Gajdusek, 1957) where the organism was found to be associated with an interstitial plasma-cell pneumonitis. It is now recognised that asymptomatic infection of many species of mammals, including man, is widespread and serological surveys of healthy human adults have revealed a prevalence of antipneumocystis antibody in $40-70 \%$ of the population (Pifer et al., 1978; Maddison et al., 1984).

The route of infection is unknown. Whilst an airborne route seems most likely, it is of interest that recent reports of spread of infection or 'outbreaks' in groups of vulnerable patients are rare. This current situation is in contrast with the early infant cases described in Europe where overcrowding and person-to-person spread were thought to be prominent features (Gajdusek, 1957). $P$. carinii pneumonitis, similar to that seen in man, can be induced in rats by subjecting them to a regimen of corticosteroids and low-protein diet (Walzer et al., 1980). It seems likely that asymptomatic infections in man become patent by similar mechanisms when the host becomes immunocompromised. As $P$. carinii pneumonitis has been described in patients with virtually any condition which reduces immunocompetence, it seems likely that impairment of either cell-mediated or humoral immunity can be sufficient to induce patency (Walzer et al., 1973; Saulsbury et al., 1979). Nevertheless, the situation is confused because adult patients with predominantly cell-mediated immunological defects are amongst the most vulnerable and, within that group, AIDS patients with their complex derangements of T-cell and B-cell function are most at risk (Lane et al., 1983; Ammann et al., 1984; Hofmann et al., 1985). Thus, AIDS patients have an annual attack rate of $c .30 \%$ (Kovacs et al., 1984) compared with rates of $0 \cdot 1-$ $1.1 \%$ in patients with leukaemia, lymphoma or renal transplants (Walzer et al., 1974). The index diagnosis in $50 \%$ of AIDS patients at the time of notification to the Centers for Disease Control (CDC, 1984) is $P$. carinii pneumonitis. $P$. carinii infection is unusual in that even in the most severely 
immunocompromised patient infection remains confined to the lungs. That strain or even specific differences exist between human and rat isolates is suggested by failure to infect rats with human isolates (Walzer and Rutledge, 1980) and the fact that, although some common antigenic determinants have been demonstrated by Western immunoblotting (Graves et al., 1986), the 2G2 monoclonal antibody produced and studied by Kovacs et al. (1986) reacted with human isolates only.

$P$. carinii pneumonitis in immunocompromised adults is characterised by a 'foamy' intra-alveolar exudate containing cysts and trophozoites. The organisms do not invade the alveolar septae but the trophozoites appear firmly attached to the type-1 pneumocyte. In infantile infections a notable pathological feature is extensive alveolar thickening with a plasma-cell infiltrate.

Definitive diagnosis rests with the demonstration of the organism by histological or immunohistological methods. Serodiagnosis by the demonstration of circulating antibodies is unreliable because of the high prevalence of seropositivity in the healthy human population (Maddison et al., 1984) and because it is to be expected that the population at risk of developing disease, by the very nature of their underlying vulnerability, will be unable to mount large enough antibody titres to be useful diagnostically. Demonstration of antigenaemia is a more attractive prospect and, whilst some promising studies have been reported (Young, 1987; Pifer et al., 1988), progress in this field awaits the development, evaluation and ready availability of suitable monoclonal or polyclonal antibodies (Walzer et al., 1987).

Whilst material obtained by open-lung biopsy still gives the greatest opportunity of demonstrating the organisms, the indications for resorting to such a procedure are now less compelling because of the increasing numbers of AIDS patients in whom a diagnosis of $P$. carinii infection requires to be confirmed or refuted. AIDS patients have a much higher organism burden than other groups of patients and it has been shown that examination of induced sputum in such patients can produce a diagnosis in $50 \%$ of cases (Pitchenik et al., 1986). Moreover, the inherent risks associated with openlung biopsy (e.g., pneumothorax and anaesthetic complications), together with increasing burdens on hospital resources, have contributed to the widespread adoption of less invasive techniques such as bronchial lavage or transbronchial biopsy with a fibre-optic bronchoscope. Fluid material, e.g., sputum, induced sputum or lavage, can be examined for trophozoites and "immature" cysts by Giemsa, polychrome methylene blue or WrightGiemsa stains. Optimal cytocentrifugation of such liquid specimens has proved helpful (Gill et al., 1988). Lung-biopsy impression smears can be examined in the same way. Young et al. (1986) found Papanicolaou staining, confirmed by the conventional Grocott methenamine silver technique, to be satisfactory. Histological material should be stained by techniques which detect the cell wall of $P$. carinii cysts. Gomori or Grocott methenamine silver techniques are the original standards but, because they are time-consuming and require experience, many pathologists have adopted more rapid alternatives such as toluidine blue $\mathrm{O}$, cresyl echt violet and Gram-Weigert. All these stains can be applied to lavage material. DNA probes for the detection of $P$. carinii are also being developed (Tanabe et al., 1988) and evaluated (Wakefield et al., 1988). Outline protocols for the laboratory diagnosis of pneumocystosis are given in table III. The current state of the diagnosis of $P$. carinii infection is well summarised by Walzer (1988) and Hopewell (1988).

\section{Toxoplasma gondii}

$T$. gondii, a coccidian protozoan parasite whose definitive hosts are members of the Felidae, was first described by Nicholle and Manceaux in 1908. These workers found the organisms in the brain of the rodent, the gondii. The parasite is distributed worldwide and an extensive range of mammalian and avian intermediate hosts has been described. Man is an intermediate host and can be infected either by the ingestion of sporulated oocysts found in cat (or other feline) faeces or, perhaps more importantly, by the ingestion of tissue cysts containing cystozoites (bradyzoites) which are present in undercooked meats such as mutton and beef. Sporozoites which are released from ingested oocysts multiply in tissue macrophages. Continued development and dissemination of the parasite is normally restricted by developing immunity. Endozoites (tachyzoites) and cystozoites are the tissue forms from which lesions can develop. Endozoites, by multiplying rapidly in host cells, produce pseudocysts which rupture to release more endozoites to invade surrounding cells. With the development of immunity, true-walled cysts are formed as multiplication is slowed down. When these cysts rupture, the released cystozoites are either killed by antibody or inhibited from development by cellular immunity. Many cysts containing viable cystozoites can remain intact for the duration of the life of the 
Table III. Summary of current procedures and techniques for the diagnosis of $P$. carinii infection

\begin{tabular}{ll}
\hline \multicolumn{1}{c}{ Specimen } & \multicolumn{1}{c}{ Technique } \\
\hline $\begin{array}{c}\text { Sputum, induced sputum, bron- } \\
\text { chial lavage, lung biopsy, } \\
\text { smears, impression smears }\end{array}$ & $\begin{array}{l}\text { Demonstration of trophozoites and 'immature' cysts } \\
\text { a. Histological stains } \\
\text { Giemsa, polychrome methylene blue, Wright-Giemsa }\end{array}$ \\
& $\begin{array}{l}\text { b. Immunohistology } \\
\text { Polyclonal and monoclonal antibodies by fluorescence }\end{array}$ \\
$\begin{array}{l}\text { Transbronchial biopsy } \\
\text { Open-lung biopsy }\end{array}$ & $\begin{array}{l}\text { Demonstration of cysts } \\
\text { Tistology }\end{array}$ \\
& Toluidine blue 0, cresyl echt violet, Gram-Weigert, methenamine \\
sera ('base line' and serial) & $\begin{array}{l}\text { Demonstration of antibodies } \\
\text { Indirect immunofluorescence, ELISA } \\
\text { (Demonstration of rising titres) }\end{array}$ \\
& $\begin{array}{l}\text { Demonstration of antigens } \\
\text { Counter-current immunoelectrophoresis, ELISA } \\
\text { Latex agglutination }\end{array}$ \\
\hline
\end{tabular}

host, including man. Impairment of acquired immunity, especially the cellular component, may result in the reactivation and dissemination of such latent infections. It is also possible that impaired immunity may result in the acquisition of infection de novo. Possible routes of infection leading to toxoplasmosis in the immunocompromised are summarised in fig. 1.

Whilst abortion, congenital abnormalities, choroido-retinitis and lymphadenopathy are wellrecognised sequelae of infection, subclinical infection is more usual and $20-40 \%$ of adults in the USA and UK have detectable circulating antibodies to T. gondii (Feldman, 1982). In patients with acquired immunodeficiency, protean neurological symptoms are predominant although other systems may be involved. The wide spectrum of neurological symptoms embraces the manifestations of underlying meningoencephalitis, diffuse encephalopathy and intracranial masses. It is suggested that such pathology is produced by the rupture of toxoplasmic cysts with the release of cystozoites which stimulate a microglial reaction (Frenkel, 1956). Just such a process has been observed histologically in a laboratory infected Panamanian night monkey (Aotus lemurinus). By means of the peroxidaseantiperoxidase technique, toxoplasma antigen was demonstrated within glial nodules (Frenkel and Escajadillo, 1987). The incidence of toxoplasmosis in the compromised host has been reviewed (Ruskin and Remington, 1976; Mills, 1986). In a review of 315 AIDS patients who suffered neurological complications, $T$. gondii was the predominant aetiological agent (103 patients) (Levy et al., 1985). The clinical and neurological findings in a further 27 AIDS patients with cerebral toxoplasmosis have

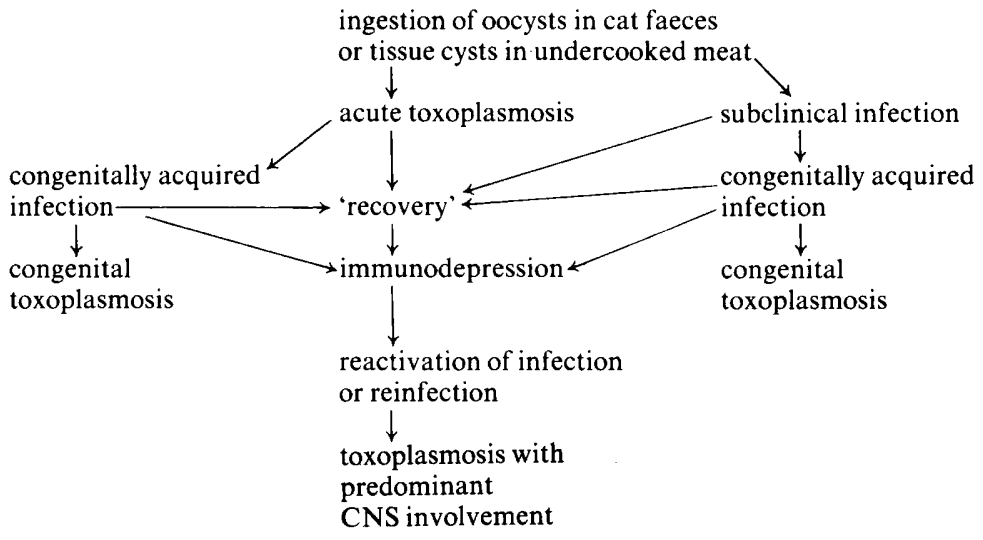

Fig. 1. Possible routes of infection leading to cerebral toxoplasmosis. 
since been described (Navia et al., 1986). The problems of making a diagnosis of toxoplasmosis in many groups of immunodeficient patients have been well documented (Lancet, 1984; Luft and Remington, 1988). As with $P$. carinii infection, because of the high level of subclinical infection in the human population and because of the extremely unpredictable immunological response to reactivated or newly acquired infections in immunocompromised groups such as AIDS patients, the conventional serum antibody tests, of which there is a large variety (Frenkel, 1985), are of limited usefulness only. However, demonstration of high titres of anti-toxoplasma IgG antibodies in serum, or any anti-toxoplasma IgM antibody in serum or CSF, is indicative of active infection, whether reactivated or newly acquired. It should be appreciated that this general statement has to be modified according to the background antibody profile of the general population and the group under study. Thus, serum IgM antibody is rarely detectable in AIDS patients in the USA whereas IgM antibody has been found in up to $20 \%$ of such patients in France. Specific IgM antibody levels in persons in those countries have been interpreted as reflecting reactivation of infection in the USA and reinfection in France (Luft and Remington, 1988). Demonstration of intrathecal antibody should be pursued even in the absence of significant serological findings; however, here again, failure to demonstrate antibodies does not exclude a diagnosis of "toxoplasmic encephalitis" (Wong et al., 1984; Potasman et al., 1988). The alternative approach of demonstrating circulating antigens in serum looks promising (Candolfi et al., 1987), but even the visualisation of parasitic cysts or parasite antigen by histological or immunohistological methods are not without problems of interpretation because of the high incidence of subclinical infection. The recovery of the parasite by inoculating mice with biopsy or cerebrospinal deposit is subject to the same limitation of interpretation. Nevertheless, because endozoites are consistently associated with active disease, the direct demonstration of such stages in tissue, impression smears or CSF deposit by staining with Wright-Giemsa stain is at present probably the only situation where a positive finding indicates a definitive diagnosis. Not surprisingly, excisional brain biopsies have been found to be more likely to reveal endozoites than needle biopsies in patients with AIDS and a cerebral mass or masses (Chan et al., 1984). The decision of when to take brain biopsies in AIDS patients remains controversial but again, as with suspected $P$. carinii lung infections, the decision to take a full excisional biopsy, as opposed to less invasive procedures, usually hinges on the likelihood that such material will give the opportunity of diagnosing other similarly presenting aetiologies such as Kaposi's sarcoma, fungal or viral infections (Luft and Remington, 1988). Potentially useful diagnostic procedures are summarised in table IV.

\section{Cryptosporidium spp.}

Cryptosporidium muris from the healthy gastric mucosa of the mouse was the first species to be described by Tyzzer in 1907. Cryptosporidium spp. are now recognised as an important cause of selflimiting human diarrhoeal disease throughout the world. Infections occur more frequently in children. The first human cases were described in 1976. In that year a case of "overwhelming watery diarrhoea" in an immunosuppressed patient (Meisel et al., 1976) and another of acute enterocolitis (Nime et al., 1976) were recorded. It is of interest that both of these cases had a history of animal contactCryptosporidium spp. had long been known to be a cause of diarrhoea in turkeys, calves and sheep. A review of the first 58 human cases reported between 1976 and 1984 revealed that 18 patients had normal immune function and 40 had some degree of immunological dysfunction, the commonest of which (33 cases) was due to AIDS (Navin and Juranek, 1984). Whilst these early reports indicated an artificially strong association between symptomatic infection and immunological deficiency, this can be explained by the general unawareness at that time of the ubiquity of human cryptosporidial

Table IV. Diagnosis of toxoplasmosis in the compromised host

\begin{tabular}{ll}
\hline Specimen & Diagnostic finding \\
\hline Serum & $\begin{array}{l}\text { High level of IgG antibodies } \\
\text { IgM antibodies present } \\
\text { Toxoplasma antigen present }\end{array}$ \\
& IgG antibody level > serum level \\
CSF & IgG antibody present in CSF only \\
& IgM antibody present \\
& Parasite in centrifuged deposit demonstrated \\
& by Gram-Weigert stain or animal inocula- \\
& tion \\
& Demonstration of : \\
& antigen or cysts by histology, immuno- \\
& histology \\
parasites by animal inoculation & *endozoites by histology
\end{tabular}

* Indicates active toxoplasmosis. 
infections. Subsequent studies have revealed stoolisolation rates of Cryptosporidium spp. of $1 \cdot 1-7 \cdot 2 \%$ in symptomatic immunocompetent patients in the UK (Fayer and Ungar, 1986). The overall incidence of cryptosporidiosis in AIDS patients reported to the Centers for Disease Control, Atlanta, GA, was $3.6 \%$ (Navin and Hardy, 1987). These authors suggest that the homosexual or bisexual activity of oro-anal intercourse accounts for the relatively high prevalence $(4.2 \%)$ of cryptosporidiosis in such patients compared with heterosexual male and female AIDS patients $(2 \cdot 1 \%)$. In immunocompromised patients, and particularly in AIDS patients, symptoms are prolonged with profuse watery diarrhoea which can be life-threatening (Malebranche et al., 1983; Modigliani et al., 1985; Gelb and Miller, 1986).

Cryptosporidium spp. have been found throughout the length of the gastrointestinal tract from pharynx to rectum with the jejunum being the most frequently affected site (Weisburger et al., 1979; Sloper et al., 1982). Involvement of the respiratory tract alone (Brady et al., 1984) or in combination with the gastrointestinal tract (Forgacs et al., 1983; Ma et al., 1984), and biliary (Margulis et al., 1986) and multisystem (Gross et al., 1986) infections have been described.

The numbers of species in the genus Cryptosporidium continue to be the subject of controversy. Whereas Tzipori argues for a single species (Tzipori et al., 1980), other workers consider that there are four species with the species $C$. parvum infecting man and cattle (Upton and Current, 1985).

Infection follows the ingestion of oocysts when up to four motile sporozoites are released in the small intestine where they adhere to enterocytes and begin development to trophozoites beneath the cell membrane. Throughout the stages of development and multiplication, the parasite remains intracellular (in a parasitophorous vacuole) but extracytoplasmic. Two forms of schizont (meront) can be produced. Type-I schizonts produce eight merozoites which, in turn, can produce either more type-I schizonts or type-II schizonts. The type-II schizonts produce the sexual stages-four merozoites differentiate into gametocytes. Microgametocytes multiply and are released as microgametes to fertilise mature macrogametes. Fertilisation results in the production of oocysts which may either produce auto-infection or be passed in the faeces. It should be noted that even in the immunodeficient host, invasion beyond the host cell-membrane does not usually occur. The diarrhoea produced, even in the most severe cases, is of a secretory nature and histological reactions are nonspecific with mononuclear infiltration of the lamina propria. Villous atrophy and malabsorption may occur (Navin, 1985). Cell-mediated immunity is probably the major mechanism of host defence as patients receiving immunosuppressive therapy suffer prolonged and severe symptoms which can be cured on cessation of therapy. It is to be noted that $\operatorname{IgM}$ and $\operatorname{IgG}$ antibodies are detectable in both normal and immunocompromised patients and that ELISA techniques to detect such antibodies have been used successfully for diagnosis in both such groups (Ungar et al., 1986).

Before 1978 diagnosis of cryptosporidiosis was dependent upon the demonstration of the stages of the parasite in biopsy material after staining with Giemsa or periodic-acid Schiff stains or by electronmicroscopy. The demonstration of oocysts in stool samples is now a routine procedure in many laboratories in many parts of the world. When a patient's symptoms are attributable to cryptosporidosis, jejunal aspirates or biopsies are seldom, if ever, necessary to make the diagnosis. Oocysts concentrate well by the Ritchie formol-ether faecal concentration procedure and, although in some hands it is considered to be inferior to the Sheather concentration method (Ma and Soave, 1983), it has the advantage of being faster, easier, and in common use. Oocysts can be identified in wet mounts viewed by transmitted light but fixing and staining of concentrates is generally preferred. The choice of staining method, of which there are at least 13 (including modifications), depends on the facilities and expertise available. Phenol-auramine has the advantage of rapidity of screening but morphological details of cysts are ill-defined. The modified Ziehl-Neelsen hot acid-fast stain with $10 \%$ potassium hydroxide digestion provides good morphological detail. Fluorescein-conjugated monoclonal antibodies are now available for diagnosis (Garcia et al., 1987) but it is debatable whether their use can be justified for faecal examination.

The topics of Cryptosporidium spp. and cryptosporidosis have been well reviewed in the last three years (Casemore et al., 1985; Fayer and Ungar, 1986; Janoff and Reller, 1987). A bibliography of the intestinal coccidia has been prepared by Cook (1987).

\section{Microsporidia}

Microsporidia are eukaryotic unicellular parasites which have been classified as occupying a single subphylum of the protozoa (Levine, 1973) or have been regarded as being sufficiently unique to justify the creation of a separate phylum-Micro- 
spora (Canning and Lome, 1986). More than 700 species of microsporidia have been described as parasites of many phyla of invertebrates and all classes of vertebrates. The first mammalian infection was recorded by Craig in 1922 when microsporidial spores were found in the brains and kidneys of rabbits. This organism, which was subsequently named Encephalitozoon cuniculi, has since been found in many mammalian species. Only three human infections with this species have been described. Two cases affected the nervous system of ostensibly immunocompetent patients (Matsubayashi et al., 1959; Bergquist et al., 1984b) and the third case was detected in the liver of an AIDS patient (Terada et al., 1987). It is of interest that, although only one case of $E$. cuniculi has been identified from immunocompromised patients, $32 \cdot 1 \%$ of patients considered to be at risk of AIDS had circulating antibodies to E. cuniculi (Bergquist et al., 1984a).

In general, thick-walled microsporidium spores measuring $c$. $5 \mu \mathrm{m}$ (range $1-12 \mu \mathrm{m}$ ) contain the sporoplasm and an unique coiled inoculation apparatus - the polar filament. When the spore is ingested, the polar filament is uncoiled and extruded to penetrate the host cell. The sporoplasm travels along the polar tube and enters the host cell where rapid multiplication by merogony and sporogony takes place. E. cuniculi develops in parasitophorous vacuoles in macrophages, endothelial cells and renal tubule cells. In this species, the sporont gives rise to two spores.

All subsequent reports of human infection with other microsporidia have come from patients who are immunocompromised or from sites which are immunologically privileged (e.g., cornea). To date, 15 cases have been reported. Excluding the two corneal cases (Ashton and Wirasinha, 1973; Pinnolis et al., 1981) details of, and references to, the other 13 systemic cases are provided in table V. It will be seen that probably 11 of the 13 cases implicated Enterocytozoon bieneusi as the cause of severe gastrointestinal upset in immunocompromised patients. En. bieneusi infects enterocytes and is in direct contact with the cytoplasm of the cell (cf., $E$. conori) occupying a site between the nucleus and the brush border. En. bieneusi is distinguished from other microsporidia by the fact that polar filament precursors are found early in the undivided sporont. Whereas all the early cases were diagnosed by electronmicroscopy of intestinal biopsies, a strong case for the examination of duodenal-biopsy material by light microscopy and Giemsa-stained impression smears has been made by Rijpstra et al. (1988). Again, the fact that these authors diagnosed three cases of microsporidium infection among 10 AIDS patients examined by duodenal biopsy for the investigation of severe diarrhoea suggests that microsporidium infection may be much more common than the small number of cases so far reported. It is, therefore, important that a search for these organisms is undertaken by all those responsible for the management of AIDS patients so that the true incidence of microsporidium infections can be established. The use of the Giemsa-stained smear technique should not be

Table V. Reported microsporidium infections in immunocompromised patients

\begin{tabular}{|c|c|c|c|c|c|}
\hline $\begin{array}{l}\text { Report } \\
\text { no. }\end{array}$ & Species & Country & Symptoms & $\begin{array}{l}\text { Diagnostic } \\
\text { method* }\end{array}$ & Reference \\
\hline 1 & Nosema conori & USA & $\begin{array}{l}\text { Disseminated infection } \\
\text { involving myocar- } \\
\text { dium, diaphragm, ar- } \\
\text { terial walls, renal } \\
\text { tubules, liver and } \\
\text { lungs }\end{array}$ & EM & Sprague, 1974 \\
\hline 2 & Pleistophora spp. & USA & $\begin{array}{l}\text { Myositis, lymphaden- } \\
\text { opathy }\end{array}$ & EM & Ledford et al., 1985 \\
\hline 3 & Enterocytozoon bieneusi & France & Severe diarrhoea & EM & Modigliani et al., 1985 \\
\hline $4-7$ & En. bieneusi & USA & Severe diarrhoea & EM & $\begin{array}{l}\text { Dobbins and Weinstein, } 1985 \text {; } \\
\text { Owen, 1987; Gourley (see Rijps- } \\
\text { tra et al., 1988) }\end{array}$ \\
\hline 8,9 & En. bieneusi & Uganda & Slim disease & LM & Lucas and Wamukota, 1987 \\
\hline $10-12$ & En. bieneusi & Netherlands & Severe diarrhoea & EM & Rijpstra et al., 1988 \\
\hline 13 & ? En. bieneusi $\dagger$ & UK & Severe diarrhoea & EM & Curry et al., 1988 \\
\hline
\end{tabular}

* EM= electronmicroscopy $; \mathrm{LM}=$ light microscopy.

$\dagger$ Not speciated at time of reporting. 
beyond the resources of most establishments. The role of mammalian microsporidians as pathogens has been the subject of a most interesting overview by Canning and Hollister (1987).

\section{Acanthamoeba spp.}

Over the past 20 years there has been increasing interest in human infections caused by the freeliving soil amoebae. Included among the small freeliving soil amoebae, with human pathological propensities, are members of the genera Naegleria, Acanthamoeba and possibly Valkampfia. Naegleria spp. (usually $N$. fowleri) are associated with an acute primary meningoencephalitis in the immunocompetent patient. There is usually a history of recent immersion in warm water and infection via the cribriform plate is thought to occur. Acanthamoeba spp. (usually $A$. castellani or $A$. culbertsoni) may cause conjunctivitis, keratitis and skin lesions in the immunocompetent host but are more usually associated with a chronic granulomatous amoebic encephalitis in immunocompromised patients. Of the 23 documented cases of Acanthamoeba spp. infections of the central nervous system, only three cases conformed to the acute meningoencephalitis syndrome associated more usually with Naegleria spp. infections (Wiley et al., 1987). Central nervous system infection with Acanthamoeba spp. is usually via the haematogenous route from primary sites in the skin or respiratory tract (lung or nasal turbinates) (Gonzalez et al., 1986). Subclinical infection of the respiratory tract is thought by some to be common (Wang and Feldman, 1967).

The first reports of granulomata of the brain caused by amoebae designated the organisms as Endolimax williamsi and Hartmanella spp. (Kernohan et al., 1960; Patras and Andujar, 1966). It is likely that both these cases would now be attributed to Acanthamoeba spp. It should be noted that, to date, amoebae have not been found before death in the cerebrospinal fluid of patients with granulomatous amoebic encephalitis, although a moderate elevation of the white-cell count may occur (cf., primary amoebic meningoenceaphalitis where $\mathrm{Nae}$ gleria spp. are frequently observed and white-cell counts may be grossly elevated). Accordingly, antemortem diagnosis is best achieved by brain biopsy. Both trophozoites and cysts are made readily recognisable by conventional haematoxylin and eosin histological staining but finer detail can be obtained by the use of trichrome or Heidenhain's iron-haematoxylin stains. Trophozoites measure $10-45 \mu \mathrm{m}$ in diameter and have characteristic spine-like processes. Cysts, measuring $10-25 \mu \mathrm{m}$, are double-walled with a wrinkled outer wall (ectocyst) and a polygonal inner wall (endocyst). The single nucleus in both trophozoite and cyst is characterised by a large dense central nucleolus. Speciation of amoebae can be attempted by means of fluorescein-conjugated antisera prepared against individual species on deparaffinised tissue sections (Martinez, 1982). Acanthamoeba spp. may be isolated from brain biopsy (or necropsy material) by intracranial inoculation into BALB/c mice, tissue culture in human embryonic kidney cells (Wiley et al., 1987) or on non-nutrient agar in the presence of Escherichia coli or Enterobacter spp. (Page, 1967). In this latter technique, plates are seeded with biopsy material incubated at $37^{\circ} \mathrm{C}$ and examined daily for $7 \mathrm{~d}$. The presence of amoebae can be detected by use of a hand lens to identify small areas of lysis due to ingestion of the lawn of bacteria by amoebae.

The pathogenic effects and the characteristics of the free-living soil amoebae were reviewed by Martinez (1983).

\section{Giardia lamblia}

Giardia lamblia is the commonest gastro-intestinal parasite of man in the Western World. The parasite has trophozoite and cystic stages. The trophozoite has a quite characteristic appearance, is pear- or kite-shaped, measures $12-18 \mu \mathrm{m}$ in length, has eight flagella, a prominent ventral sucking disk and two oval nuclei with prominent karyosomes. The cyst is oval, 7-14 $\mu \mathrm{m}$ in length and, when mature, has four nuclei and a diagonal axoneme. Multiplication occurs in both trophozoite and cystic stages. Infection is by ingestion of cysts and is usually by the faecal-oral route. Excystation takes place in the small intestine and a fournucleated "trophozoite" emerges and immediately divides. The trophozoites live in the small intestine and induce a mild inflammatory infiltrate of the lamina propria with flattening of the villi in more severe and prolonged infections. Infection is usually self-limiting after 6 weeks. That humoral immunity may be important in self-cure and protection against re-infection is indicated by the demonstration of antibody-dependent killing of G. lamblia trophozoites in vitro (Smith et al., 1983; Hill et al., 1984). Similarly, there is an increased prevalence of giardiasis in hypogammaglobulinaemic and $\operatorname{IgA} \mathrm{A}_{2}$ deficient patients (Hausser et al., 1983) and in some such patients symptoms may be more severe or prolonged (Perlmutter et al., 1985) or fail to clear (Owen, 1980). Indeed, continued failure of appropriate antiprotozoal agents (e.g., metronidazole and 
mepacrine) to effect clinical and parasitological cure should suggest the possibility of underlying immunological insufficiency. As with other gastrointestinal protozoa transmitted by the faecaloral route (e.g., Cryptosporidium spp., I. belli, Entamoeba histolytica and commensal amoebae), there is a higher rate of infection in homosexual men than in the corresponding heterosexual population (Schmerin et al., 1978; William et al., 1978). Patients with AIDS and acute symptomatic giardiasis have reduced levels of specific IgG, IgM and IgA when compared with similarly infected and symptomatic heterosexual non-AIDS patients (Janoff et al., 1988).

The diagnosis of giardiasis by the demonstration of trophozoites, cysts or parasite antigen (Green et al., 1985) in faeces or by the demonstration of trophozoites in duodenal aspirates poses no special problem in infected immunocompromised patients.

\section{Isospora belli}

I. belli is a coccidian parasite of the intestinal tract of man. The parasite has a worldwide distribution but is most common in Africa, South America and South-East Asia. Man is the only known host. Infection is by the faecal-oral route and homosexual activity predisposes to infection (Ma et al., 1984; Forthal and Guest, 1984). Whilst infection may be asymptomatic, symptoms in immunocompromised patients, and especially in AIDS patients, may be severe and prolonged (Whiteside et al., 1984). In such patients a clinical picture similar to that found in cryptosporidiosis may occur and it is of interest that concomitant infection with both coccidians is not uncommon (Modigliani et al., 1985; Gelb and Miller, 1986). I. belli has been found in $15 \%$ of Haitian AIDS sufferers (de Hovits et al., 1986). A fatal case of disseminated isosporiasis has been described (Restrepo et al., 1987).

Infection is by ingestion of oocysts. The mature oocyst contains two sporocysts and each sporocyst contains four sporozoites, which are released in the small intestine and invade enterocytes to become trophozoites. The trophozoite multiples to produce a schizont which ruptures with the containing enterocyte to release merozoites. The merozoites invade further enterocytes and the sexual phase of the life cycle commences with the development, via gametocytes, of micro- and macrogametes which fuse to produce a zygote. The zygote matures to produce an oocyst which, when passed in the faeces, has not usually sporulated. The mature oocyst is ovoidal measuring some $20-30 \mu \mathrm{m}$ by $10-18 \mu \mathrm{m}$ and is sufficiently large not to be missed on microscopy of wet faecal films but, because they may be scanty and excreted intermittently, formolether concentration of faeces or duodenal aspiration may be necessary to establish the diagnosis. Some workers advocate the use of staining techniques such as modified Ziehl-Neelsen to facilitate diagnosis (Soave and Johnson, 1988).

\section{Leishmania donovani}

$L$. donovani is the causative agent of human visceral leishmaniasis, kala-azar The disease is widespread in the tropics and subtropics and extends, with lower endemicity, to the Mediterranean littoral. Transmission is by the bite of the sandfly (Phlebotomus spp.) when the promastigote is inoculated into the vertebrate host. The promastigotes are ingested by macrophages and transform into amastigotes. The oval amastigotes, measuring 2-3 $\mu \mathrm{m}$, are parasites of polymorphonuclear cells, monocytes and endothelial cells. Visceral leishmaniasis is primarily a disease of the haemopoietic system, classically characterised by hepatosplenomegaly and hyperglobulinaemia. It should be noted that visceral leishmaniasis per se may result in depression of cell-mediated immunity (Mauel and Behin, 1982) but $L$. donovani infection is included in this overview because of recent reports of the organism acting in opportunist infection in therapeutically immunodepressed patients (Badaro et al., 1986; de Letona et al., 1986) and in AIDS patients (Clauvel et al., 1986; Senaldi et al., 1986; Montalban et al., 1987). Further evidence which suggests that visceral leishmaniasis may be an opportunist infection has been accrued by a recent study in Brazil where malnutrition was implicated as an important risk factor for severe disease (Cerf et al., 1987). Diagnosis is by the conventional techniques of the demonstration histologically of amastigotes in bone marrow or splenic-puncture smears or by the culture of promastigotes from similar material.

\section{Babesia divergens}

Babesia spp. are pleomorphic obligate intraerythrocytic protozoa tentatively ascribed to the subphylum Apicomplexa. Although first described by Babes as long ago as 1888 in the blood of cattle and sheep in Romania, knowledge of these parasites remains relatively rudimentary. The number of species found in mammals is undecided. Levine (1971) listed 71 reported species, but it is suggested that many of these are synonyms. All known species 
are arthropod-transmitted with ixodid ticks of various species being the most frequently involved. Human infection has been described with $B$. microti (a rodent species) in apparently immunocompetent patients in the eastern USA and with $B$. divergens (a bovine species) in splenectomised patients in Europe (Entrican et al., 1979). It is because of the latter that $B$. divergens has been included in this overview.

Human $B$. divergens infections, whilst still rare, are usually fatal. Up to $80 \%$ of peripheral red-blood cells may be parasitised and multiple infections within individual red blood cells are common. The parasites may present dot, rod, club, "Maltese cross" and ring-form appearances. The latter superficially resemble the early trophozoite stage of Plasmodium falciparum infections. The organisms are readily demonstrated in thin blood films stained by Romanowsky stains at $\mathrm{pH} 7 \cdot 2$. It has been suggested that inoculation of blood into the Mongolian gerbil (Meriones unguiculatus) may be useful in detecting light parasitaemias. Although human babesiosis is at present something of a rarity, the increasing numbers and diversity of immunocompromised individuals suggests that human babesiosis may present more frequently in the future to
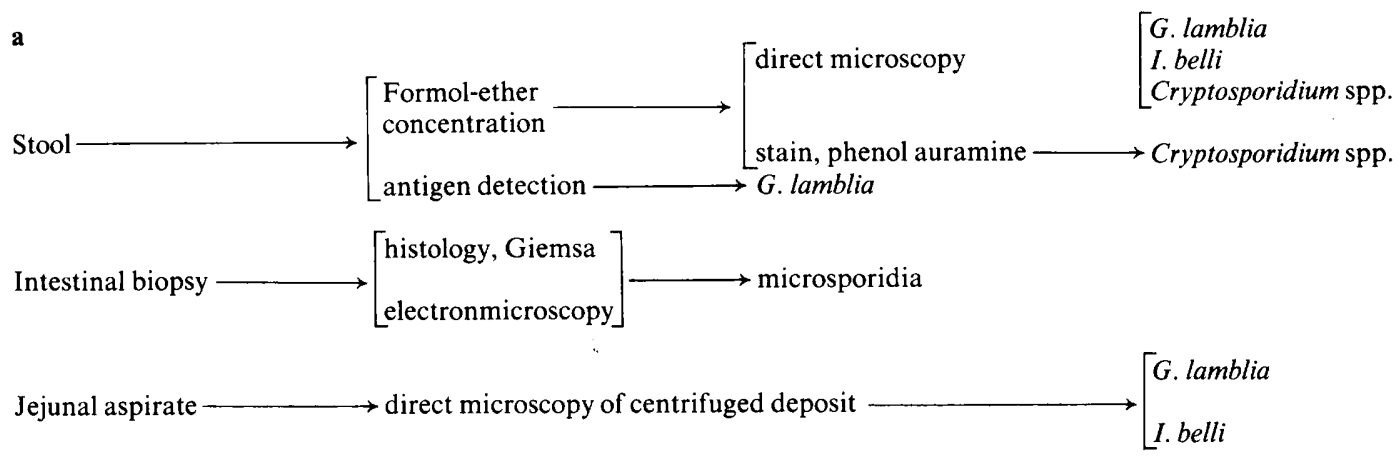

Serum $\longrightarrow$ antibodies $\longrightarrow$ G. lamblia

b

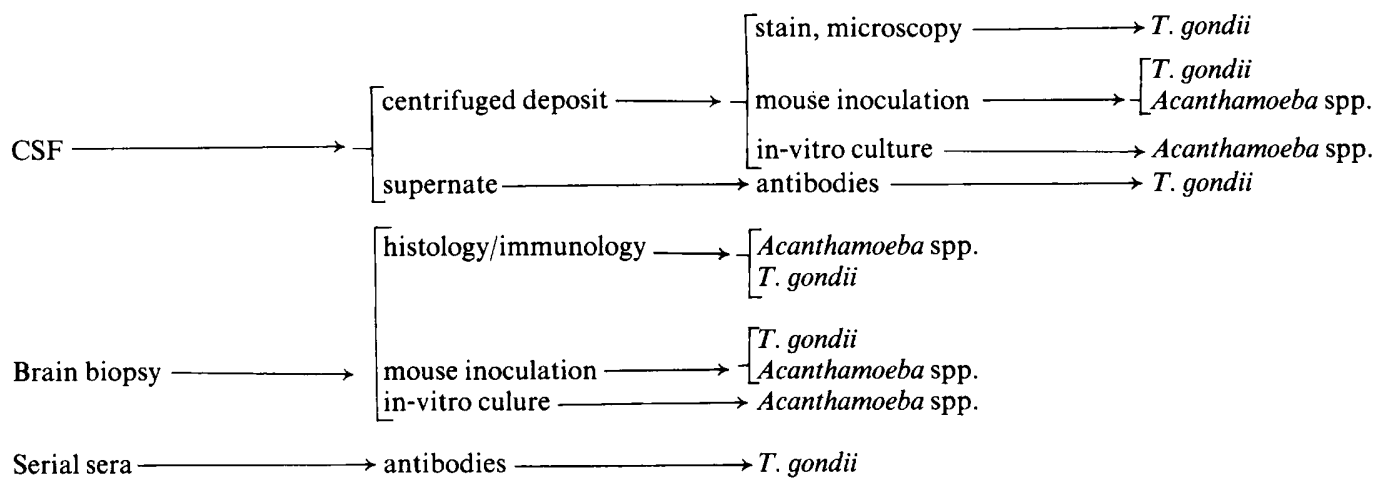

Peripheral blood $\longrightarrow\left[\begin{array}{l}\text { stained thin films } \longrightarrow \text { B. divergens } \\ \text { animal inoculation } \longrightarrow \text { L. donovani }\end{array}\right.$

$\left.\begin{array}{l}\text { Bone marrow, } \\ \text { liver/spleen biopsy }\end{array}\right] \longrightarrow\left[\begin{array}{l}\text { stain, microscopy } \\ \text { in-vitro culture }\end{array}\right] \longrightarrow$ L. donovani

Fig. 2. Outline protocol for investigating immunocompromised patients with symptoms relating to (a) gastrointestinal tract, (b) central nervous system, and (c) haemopoeitic system. 
those who are clinically aware. Babesia in man and wild and laboratory mammals has been reviewed by Ristic and Lewis (1977).

\section{Conclusions}

Whilst all of the parasites discussed in this overview have been known for more than 50 years, much of our basic understanding of these organisms and their interactions with the human host remains fragmentary. It is to be hoped that the recent surge of interest and research in protozoans stimulated by the recognition of AIDS in the Western World will continue to expand. Quite apart from the

\section{REFERENCES}

Ammann A J, Schiffman G, Abrams D, Volberding P, Zeigler J, Conant M 1984 B-cell immunodeficiency in Acquired Immune Deficiency Syndrome. Journal of the American Medical Association 251 : 1447-1449.

Ashton N, Wirasinha P A 1973 Encephalitozoonosis (nosematosis) of the cornea. British Journal of Ophthalmology 57: 669-674.

Badaro R, Carvalho E M, Rocha H, Queiroz A C, Jones T C 1986 Leishmania donovani: an opportunistic microbe associated with progressive disease in three immunocompromised patients. Lancet $1: 647-648$.

Bergquist R, Mordfeldt-Mansson L, Pehrson P O, Petrini B, Wasserman J 1984a Antibody against Encephalitozoon cuniculi in Swedish homosexual men. Scandinavian Journal of Infectious Diseases 16: 389-391.

Bergquist N R, Stintzing G, Smedman L, Waller T, Anderson T $1984 b$ Diagnosis of encaphalitozoonosis in man by serological tests. British Medical Journal 288: 902.

Brady E M, Margolis M L, Koreniowski O M 1984 Pulmonary cryptosporidiosis in acquired immune deficiency syndrome. Journal of the American Medical Association 252: 89-90.

Candolfi E, Derouin F, Klein T 1987 Detection of circulating antigens in immunocompromised patients during reactivation of chronic toxoplasmosis. European Journal of Clinical Microbiology 6: 44-88.

Canning E U, Hollister W S 1987 Microsporidia of mammalswidespread pathogens or opportunistic curiosities? Parasitology Today 3: 267-273.

Canning E U, Lome J 1986 The microsporidia of vertebrates. Academic Press, London.

Casemore D P, Armstrong M, Sands R L 1985 Laboratory diagnosis of cryptosporidiosis. Journal of Clinical Pathology 38: 1337-1341.

Centers for Disease Control 1984 Acquired immunodeficiency syndrome (AIDS) weekly surveillance report. United States Department of Health and Human Services. December 3.

Cerf B J, Jones T C, Badaro R, Sampaio D, Teixeira R, Johnson W D 1987 Malnutrition as a risk factor for severe visceral leishmaniasis. Journal of Infectious Diseases 156: 1030-1032.

Chan J C, Hensley G T, Moskowitz L B 1984 Toxoplasmosis in the central nervous system. Annals of Internal Medicine 100: 615-616.

Clauvel J P, Couderc L J, Belmin J, Daniel M T, Rabian C, Seligmann M 1986 Visceral leishmaniasis complicating justifiable concern about parasite infections in AIDS patients, the increased therapeutic use of immunosuppressive agents and the ever increasing gap between world population size and adequate nutrition means that vulnerability to opportunist protozoan infections will assume even greater significance in the future. Clinical awareness of the possibility of such protozoan infections, sometimes in patients who are not obviously at risk, together with familiarity with current laboratory procedures (and their limitations) for their diagnosis, is essential.

Outline protocols for investigating immunocompromised patients for protozoan infections are summarised in table III and fig. 2.

acquired immunodeficiency syndrome (AIDS). Transactions of the Royal Society of Tropical Medicine and Hygiene 80: 1010-1011.

Cook G C 1987 Cryptosporidium sp. and other intestinal coccidia : a bibliography. Bureau of Hygiene and Tropical Diseases, London.

Curry A, McWilliam L J, Haboubi N Y, Mandal B K 1988 Microsporidiosis in a British patient with AIDS. Journal of Clinical Pathology 41 : 477-478.

de Hovits J A, Pape J W, Boncy M, Johnson W D 1986 Clinical manifestations and therapy of Isospora belli infection in patients with the acquired immunodeficiency syndrome. New England Journal of Medicine 315 : 87-90.

de Letona J M L, Vazquez C M, Maestu R P 1986 Visceral leishmaniasis as an opportunistic infection. Lancet 1: 1094.

Dobbins W O, Weinstein W M 1985 Electron microscopy of the intestine and rectum in acquired immune deficiency syndrome. Gastroenterology 88: 738-749.

Edman J C, Kovacs J A, Masur H, Santi D V, Elwood H J, Sogin M L 1988 Ribosomal RNA sequence shows Pneumocystis carinii to be a member of the fungi. Nature 334: 519522.

Entrican J H et al. 1979 Babesiosis in man: report of a case from Scotland with observations on the infecting strain. Journal of Infection 1 : 227-234.

Fayer R, Ungar B L P 1986 Cryptosporidium spp. and cryptosporidiosis. Microbiological Reviews 50: 458-483.

Feldman H A 1982 Epidemiology of toxoplasma infection. Epidemiologic Reviews 4: 204-213.

Forgacs $\mathrm{P}$ et al. 1983 Intestinal and bronchial cryptosporidiosis in an immunodeficient homosexual man. Annals of Internal Medicine 99: 793-794.

Forthal D N, Guest S S 1984 Isospora belli enteritis in three homosexual men. American Journal of Tropical Medicine and Hygiene 33 : 1060-1064.

Frenkel J K 1956 Pathogenesis of toxoplasmosis and of infections with organisms resembling toxoplasma. Annals of the New York Academy of Science 64: 215-251.

Frenkel J K 1985 Toxoplasmosis. Pediatric Clinics of North America 32: 917-923.

Frenkel J K, Escajadillo A 1987 Cyst rupture as a pathogenic mechanism of toxoplasmic encephalitis. American Journal of Tropical Medicine and Hygiene 36: 517-522.

Gajdusek D C 1957 Penumocystis carinii-etiologic agent of interstitial plasma cell pneumonia of premature and young infants. Pediatrics 19: 543-565. 
Garcia L S, Brewer T C, Bruckner D A 1987 Fluorescence detection of Cryptosporidium oocysts in human fecal specimens by using monoclonal antibodies. Journal of Clinical Microbiology 25: 119-121.

Gelb A, Miller S 1986 AIDS and gastroenterology. American Journal of Gastroenterology 81 : 619-622.

Gill V J, Nelson N A, Stock F, Evans G 1988 Optimal use of the cytocentrifuge for recovery and diagnosis of Pneumocystis carinii in bronchoalveolar lavage and sputum specimens. Journal of Clinical Microbiology 26: 1641-1644.

Gonzalez M M et al. 1986 Acquired immunodeficiency syndrome associated with Acanthamoeba infection and other opportunistic organisms. Archives of Pathology and Laboratory Medicine 110: 749-751.

Graves D C, McNabb S J N, Ivey M H, Worley M A 1986 Development and characterization of monoclonal antibodies to Pneumocystis carinii. Infection and Immunity 51 : 125133.

Green E L, Miles M A, Warhurst D C 1985 Immuno-diagnostic detection of Giardia antigen in faeces by a rapid visual enzyme-linked immunosorbent assay. Lancet 2: 691-693.

Gross T L, Wheat J, Bartlett M, O'Connor K W 1986 AIDS and multiple system involvement with Cryptosporidium. American Journal of Gastroenterology 81 : 456-458.

Hausser C, Virelizier J-L, Buriot D, Griscelli C 1983 Common variable hypogammaglobulinemia in children. Clinical and immunologic observations in 30 patients. American Journal of Diseases of Childhood 137: 833-837.

Hill D R, Burge J J, Pearson R D 1984 Susceptibility of Giardia lamblia trophozoites-the lethal effect of human serum. Journal of Immunology 132: 2046-2052.

Hofmann B, Odum N, Platz P, Ryder L P, Svejgaard A, Neilsen J O 1985 Immunological studies in acquired immunodeficiency syndrome: function studies of lymphocyte subpopulations. Scandinavian Journal of Immunology 21 : 235-243.

Hopewell P C 1988 Pneumocystis carinii pneumonia: diagnosis. Journal of Infectious Diseases 157: 1115-1119.

Janoff E N, Reller L B 1987 Cryptosporidium species, a protean protozoan. Journal of Clinical Microbiology 25: 967-975.

Janoff E N, Smith P D, Blaser M J 1988 Acute antibody responses to Giardia lamblia are depressed in patients with AIDS. Journal of Infectious Diseases 157: 798-804.

Kernohan J W, Magath T B, Schloss G T 1960 Granuloma of the brain probably due to Endolimax williamsi (Iodamoeba butschlii). Archives of Pathology 70: 576-580.

Kovacs J A et al. 1984 Pneumocystis carinii pneumonia: a comparison between patients with the acquired immunodeficiency syndrome and patients with other immunodeficiencies. Annals of Internal Medicine 100: 663-671.

Kovacs J A et al. 1986 Prospective evaluation of a monoclonal antibody in diagnosis of Pneumocystis carinii pneumonia. Lancet 2: 1-3.

Lancet (Leading article) 1984 Toxoplasmosis diagnosis and immunodeficiency. Lancet 1 : 605-606.

Lane H C, Masur H, Edgar L C, Whalen G, Rook A H, Fauci A S 1983 Abnormalities of B-cell activation and immunoregulation in patients with the acquired immunodeficiency syndrome. New England Journal of Medicine 309: 453-458.

Ledford D K, Overman M D, Gonzalvo A, Cali A, Mester S W, Lockey R F 1985 Microsporidiosis myositis in a patient with the acquired immunodeficiency syndrome. Annals of Internal Medicine 102: 628-630.

Levine N D 1971 Taxonomy of the piroplasms. Transactions of the American Microscopical Society $90: 2-33$.

Levine N D 1973 Protozoan parasites of domestic animals and of man, 2nd edn. Burgess, Minneapolis.

Levy R M, Bredesen D E, Rosenblum M L 1985 Neurological manifestations of the acquired immunodeficiency syndrome (AIDS): experience at UCSF and review of the literature. Journal of Neurosurgery 62: 475-495.

Lucas S B, Wamukota W 1987 Human immunodeficiency virus and the local African population. In: Pounder R. E, Chiodini P L (eds) Advanced medicine 23. Bailliére Tindall, London, pp 102-111.

Luft B J, Remington J S 1988 Toxoplasmic encephalitis. Journal of Infectious Diseases 157: 1-6.

Ma P, Kaufman D, Montana J 1984 Isospora belli diarrheal infection in homosexual men. AIDS Research 1 : 327-338.

Ma P, Soave R 1983 Three step stool examination for cryptosporidiosis in 10 homosexual men with protracted watery diarrhea. Journal of Infectious Diseases 147: 824828 .

Ma P, Villaneuva T G, Kaufman D, Gillooley J F 1984 Respiratory cryptosporidiosis in the acquired immune deficiency syndrome. Use of modified cold Kinyoun and Hemacolor stains for rapid diagnoses. Journal of the American Medical Association 252: 1298-1301.

Maddison S E, Walls K W, Haverkos H W, Juranek D D 1984 Evaluation of serological tests for Pneumocystis carinii antibody and antigenemia in patients with acquired immunodeficiency syndrome. Diagnostic Microbiology and Infectious Disease 2: 69-73.

Malebranche $\mathrm{R}$ et al. 1983 Acquired immunodeficiency syndrome with severe gastrointestinal manifestations in Haiti. Lancet 2: 873-877.

Margulis S J, Honig C L, Soave R, Govoni A F, Mouradian J A, Jacobson I M 1986 Biliary tract obstruction in the acquired immuno-deficiency syndrome. Annals of Internal Medicine 105: 207-210.

Martinez A J 1982 Acanthamoebiasis and immuno-suppression. Case report. Journal of Neuropathology and Experimental Neurology 41 : 548-557.

Martinez A J 1983 Free living amoebae: pathogenic aspects. A review. Protozoological Abstracts, Commonwealth Institute of Parasitology 7: 293-306.

Matsubayashi H, Koike T, Mikata I, Takei H, Hagiwara S 1959 A case of Encephalitozoon-like body infection in man. Archives of Pathology 67: 181-187.

Mauel J, Behin R 1982 Leishmaniasis: immunity, immunopathology and immunodiagnosis. In: Cohen S, Warren K S (eds) Immunology of parasitic infections, 2nd edn. Blackwell, Oxford, pp 299-355.

Meisel J L, Perera D R, Meligro C, Robin C E 1976 Overwhelming watery diarrhea associated with a cryptosporidium in an immunocompromised patient. Gastroenterology 70: 1156-1160

Mills J 1986 Pneumocystis carinii and Toxoplasma gondii infections in patients with AIDS. Reviews of Infectious Diseases 8: 1001-1011

Modigliani $\mathrm{R}$ et al. 1985 Diarrhoea and malabsorption in acquired immune deficiency syndrome: a study of four cases with special emphasis on opportunistic protozoan infestations. Gut 26: 179-187.

Montalban C, Sevilla F, Moreno A, Nash R, Celma M L, Munoz R F 1987 Visceral leishmaniasis as an opportunistic infection in the acquired immunodeficiency syndrome. Journal of Infection 15: 247-250.

Navia B A, Petito C K, Gold J W M, Cho E-S, Jordan B D, Price R W 1986 Cerebral toxoplasmosis complicating the acquired immune deficiency syndrome : clinical and neuropathological findings in 27 patients. Annals of Neurology 19 : 224-338.

Navin T R 1985 Cryptosporidiosis in humans : review of recent 
epidemiological studies. European Journal of Epidemiology 1: 77-83.

Navin T R, Hardy A M 1987 Cryptosporidiosis in patients with AIDS. Journal of Infectious Diseases 155: 150.

Navin T R, Juranek D D 1984 Cryptosporidiosis: clinical, epidemiologic and parasitologic review. Reviews of Infectious Diseases 6: 313-327.

Nime F A, Burek J D, Page D L, Holscher M A, Yardley J H 1976 Acute enterocolitis in a human being infected with the protozoan cryptosporidium. Gastroenterology 70: 592598.

Owen R L 1980 The immune response in clinical and experimental giardiasis. Transactions of the Royal Society of Tropical Medicine and Hygiene 74 : 443-445.

Owen R L 1987 Intestinal Microsporidia infection in humans: clinical description and diagnostic approach. Abstract J18, Proceedings of the Annual meeting of the American Society for Microbiology. American Society for Microbiology, Washington, D.C.

Page F C 1967 Taxonomic criteria for limax amoebae with descriptions of 3 new species of Hartmannella and 3 of Vahlkampfia. Journal of Protozoology 14 : 499-521.

Patras D, Andujar J J 1966 Meningoencephalitis due to Hartmannella (Acanthamoeba). American Journal of Clinical Pathology 46: 226-233.

Perlmutter D H, Leichtner A M, Goldman H, Winter H S 1985 Chronic diarrhea associated with hypogamma-globulinemia and enteropathy in infants and children. Digestive Diseases and Sciences 30: 1149-1155.

Pifer L L, Hughes W T, Stango S, Woods D 1978 Pneumocystis carinii infection: evidence for high prevalence in normal and immunosuppressed children. Pediatrics 61 : 35-41.

Pifer L L W, Woods D R, Edwards C C, Joyner R E, Anderson F J, Arhert K 1988 Pneumocystis carinii serologic study in pediatric acquired immunodeficiency syndrome. American Journal of Diseases of Children 142: 36-39.

Pinnolis M, Egbert P P, Font R L, Winter F C 1981 Nosematosis of the cornea: case report including electron microscopic studies. Archives of Ophthalmology 99: 1044-1047.

Pitchenik A E, Ganjei P, Torres A, Evans D A, Rubin E, Baier H 1986 Sputum examination for the diagnosis of Pneumocystis carinii pneumonia in the acquired immunodeficiency syndrome. American Review of Respiratory Diseases 133: 226-229.

Potasman I, Resnick L, Luft B J, Remington K 1988 Intrathecal production of antibodies against $T$. gondii in patients with toxoplasmic encephalitis and AIDS. Annals of Internal Medicine 108: 49-51.

Restrepo C, Macher A M, Radany E H 1987 Disseminated extraintestinal isosporiasis in a patient with acquired immune deficiency syndrome. American Journal of Clinical Pathology 87: 536-542.

Rijpstra A C, Canning E U, Van Ketel R J, Eeftinck Schattenkerk J K M, Laarman J J 1988 Use of light microscopy to diagnose small-intestinal microsporidiosis in patients with AIDS. Journal of Infectious Diseases 157: 827831.

Ristic M, Lewis G E 1977 Babesia in man and wild and laboratory adapted mammals. In: Kreier J P (ed) Parasitic protozoa IV. Academic Press, New York, pp 53-76.

Ruskin J, Remington J S 1976 Toxoplasmosis in the compromised host. Annals of Internal Medicine 84: 193-198.

Saulsbury F T, Bernstein M T, Winkelstein J A 1979 Pneumocystis carinii pneumonia as the presenting infection in congenital hypogammaglobulinemia. Journal of Pediatrics 95 : $559-561$.

Schmerin M J, Jones T C, Klein H 1978 Giardiasis: associated with homosexuality. Annals of Internal Medicine 88: 801803.

Sloper K S, Dourmashkin R R, Bird R B, Slavin G, Webster A D B 1982 Chronic malabsorption due to cryptosporidiosis in a child with immunoglobulin deficiency. Gut 23: 80-82.

Smith P D, Keister D B, Elson C O 1983 Human host response to Giardia lamblia II. Antibody-dependent killing in vitro. Cellular Immunology 82: 308-315.

Soave R, Johnson W D 1988 Cryptosporidium and Isospora belli infections. Journal of Infectious Diseases 157: 225-229.

Sprague V 1974 Nosema connori $\mathrm{n}$. sp., a microsporidian parasite of mán. Transactions of the American Microscopical Society 93: 400-403.

Tanabe K, Fuchimoto M, Egawa K, Nakamura Y 1988 Use of Pneumocystis carinii genomic DNA clones for DNA hybridization analysis of infected human lungs. Journal of Infectious Diseases 157: 593-596.

Terada S, Reddy K R, Jeffers L J, Cali A, Schiff E R 1987 Microsporidian hepatitis in the acquired immunodeficiency syndrome. Annals of Internal Medicine 107: 61-62.

Tzipori S, Angus K W, Campbell I, Gray E W 1980 Cryptosporidium: evidence for a single species genus. Infection and Immunity 30: 884-886.

Ungar B L P, Soave R, Fayer R, Nash T E 1986 Enzyme immunoassay detection of immunoglobulin $\mathbf{M}$ and $G$ antibodies to Cryptosporidium in immunocompetent and immunocompromised persons. Journal of Infectious Diseases 153: $570-578$.

Upton S J, Current W L 1985 The species of Cryptosporidium (Apicomplexa: Cryptosporidiidae) infecting mammals. Journal of Parasitology 71: 625-629.

Wakefield A E, Hopkin J M, Burns J, Hipkiss J B, Stewart T J, Moxon E R 1988 Cloning of DNA from Pneumocystis carinii. Journal of Infectious Diseases 158: 859-862.

Walzer P D 1988 Diagnosis of Pneumocystis carinii pneumonia. Journal of Infectious Diseases 157: 629-632.

Walzer P D, Rutledge M E 1980 Comparison of rat, mouse and human Pneumocystis carinii by immunofluorescence. Journal of Infectious Diseases 142: 449.

Walzer P D et al. 1987 Serology and $P$. carinii. Chest 91 : 935.

Walzer P D, Perl D P, Krogstad D J, Rawson P G, Schultz M G 1974 Pneumocystis carinii pneumonia in the United States. Annals of Internal Medicine 80: 83-93.

Walzer P D, Schultz M G, Western K A, Robbins J B 1973 Pneumocystis carinii pneumonia and primary immune deficiency diseases of infancy and childhood. Journal of Pediatrics 82: 416-422.

Walzer P D, Powell R. D, Yoneda K, Rutledge M E, Milder J E 1980 Growth characteristics and pathogenosis of experimental Pneumocystis carinii pneumonia. Infection and Immunity 27: 928-937.

Wang S S, Feldman H A 1967 Isolation of Hartmannella species from human throats. New England Journal of Medicine 277: 1174-1179.

Weisburger W R, Hutcheon D F, Yardley J H, Roche J C, Hillis W D, Charache P 1979 Cryptosporidiosis in an immunosuppressed renal-transplant recipient with $\operatorname{IgA}$ deficiency. American Journal of Clinical Pathology 72: 473-478.

Whiteside M E, Barkin J S, May R G, Weiss S D, Fischl M A, MacLeod C L 1984 Enteric coccidiosis among patients with the acquired immunodeficiency syndrome. American Journal of Tropical Medicine and Hygiene 33: 1065-1072.

Wiley C A et al. 1987 Acanthamoeba meningoencephalitis in a patient with AIDS. Journal of Infectious Diseases 155: 130 133.

William D C, Shookhoff H B, Felman Y M, De Ramos S W 1978 High rates of enteric protozoal infections in selected 
homosexual men attending a venereal disease clinic. Sexually Transmitted Diseases 5: 155-157.

Wong B et al. 1984 Central-nervous-system toxoplasmosis in homosexual men and parenteral drug abusers. Annals of Internal Medicine 100: 36-42.

Yoneda K, Walzer P D 1980 Interaction of Pneumocystis carinii with host lungs: an ultrastructural study. Infection and Immunity 29 : 692-703.

Yoneda K, Walzer P D 1983 Attachment of Pneumocystis carinii to type 1 alveolar cells: studied by freeze-fracture electron microscopy. Infection and Immunity 40: 812-815.

Young J A, Stone J W, McGonigle R J S, Adu D, Michael J 1986 Diagnosing Pneumocystis carinii pneumonia by cytological examination of bronchoalveolar lavage fluid: report of 15 cases. Journal of Clinical Pathology 39: 945-949.

Young L S 1987 Antigen detection in Pneumocystis carinii pneumonia. Serodiagnosis and Immunotherapy 1: 163-165. 